\title{
Surgery first - prediction of surgical movements based on untreated cases
}

\author{
Thomas Stamm ${ }^{*}$, Susanne Jung ${ }^{2}$, Gudrun Prigge ${ }^{2}$, Johannes Kleinheinz ${ }^{2}$ \\ From IBRA Conference on Surgery of the Head, 6th International Orthognathic Surgery Forum \\ Interlaken, Switzerland. 14-15 February 2014
}

\begin{abstract}
Aim
The aim of the study was to test the following hypothesis: There is no difference in orthognathic surgery protocols planned on pre-treatment patient records (Surgery First protocols) compared to surgery protocols planned on patient records after orthodontic preparation (Surgery Late protocols).
\end{abstract}

\section{Material and methods}

Study type: Prospective, randomised, semi blinded trial. One hundred fifteen traditional treated orthognathic surgery cases were included based on inclusion and exclusion criteria. Pre-treatment records of the 115 cases were presented to a surgery team (surgeons, orthodontists) to generate a Surgery First protocol. The Surgery First protocols were then compared with the true (Surgery Late) protocols of the treated cases. The statistical power was $95 \%$.

\section{Results}

Surgery First and Surgery Late protocols of the same cases differ significantly. Impaction of the maxilla is the most predictable surgical movement with a mean error radius of $2.4 \mathrm{~mm} \pm 1.9 \mathrm{~mm}$ for each measurement landmark. Maxillary advancement showed an error radius of $3.2 \mathrm{~mm}$ $\pm 2.9 \mathrm{~mm}$. The highest errors were found in mandibular advancement / set back with $6.3 \mathrm{~mm} \pm 4.3 \mathrm{~mm}$ on each side. Overall the errors add up to $14.8 \mathrm{~mm} \pm 6.8 \mathrm{~mm}$. Angle classes do not differ significantly concerning the planning errors.

\section{Discussion and conclusion}

The hypothesis that there is no difference between Surgery First and Surgery Late protocols must be rejected. Planning errors with the Surgery First concept are not predictable. The post-operative malocclusion generated

${ }^{1}$ Department of Orthodontics, University Clinic Münster, Münster, Germany Full list of author information is available at the end of the article with Surgery First could lead to situations which are not manageable with orthodontics. There is a high risk of unfavourable occlusion and further corrective surgery at the end of treatment. The initial Angle class is not a valid predictor of low or high planning errors.

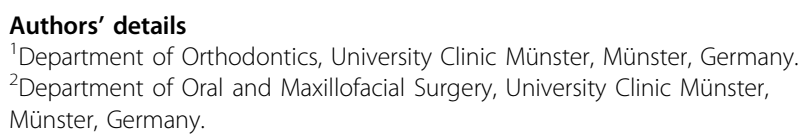

Published: 12 December 2014

doi:10.1186/1746-160X-10-S1-O3

Cite this article as: Stamm et al:: Surgery first - prediction of surgical movements based on untreated cases. Head and Face Medicine 2014 10(Suppl 1):03.
Submit your next manuscript to BioMed Central and take full advantage of:

- Convenient online submission

- Thorough peer review

- No space constraints or color figure charges

- Immediate publication on acceptance

- Inclusion in PubMed, CAS, Scopus and Google Scholar

- Research which is freely available for redistribution

Submit your manuscript at www.biomedcentral.com/submit
() Biomed Central 